\title{
Estimating nutrient concentrations from catchment characteristics across the UK
}

\author{
Helen Davies and Colin Neal \\ Centre for Ecology and Hydrology, Maclean Building, Crowmarsh Gifford, Wallingford, OXON, OX10 8BB, UK
}

Email for corresponding author: hnd@ceh.ac.uk

\begin{abstract}
Within a Geographical Information System (GIS) framework, the distributions of nitrate and orthophosphate concentrations at monitoring sites across the UK were examined and empirical relationships with catchment characteristics were established. The mean orthophosphate concentrations were linked strongly with the urban component, and less significantly with effective rainfall and agricultural coverage. This is of strategic importance in relation to phosphorus and the Water Framework Directive. Correspondingly, mean nitrate concentrations were linked to land-use types, base flow index and effective rainfall. Within-catchment residence times and effective-rainfall (runoff) were important in relation to nitrate. The issue of nitrate and the Water Framework Directive is more complex than that for orthophosphate and involves a strong agricultural as well as an urban component.
\end{abstract}

Keywords: nitrate, phosphate, orthophosphate, river, Water Framework Directive, harmonised monitoring scheme, LOIS, Humber, GIS, catchment characteristics

\section{Introduction}

In the UK, there are regional concerns over the effects of nitrogen and phosphorus on water resources, eutrophication and amenity value (EA, 2000; Pretty et al., 2003; RPA, 2003). Nitrogen and phosphorus reside in different forms within the riverine and lacustrine environments. The most common dissolved species are nitrate and orthophosphate (sometimes known as phosphate or soluble reactive phosphorus), which are also the forms of critical environmental concern, although for phosphorus the particulate form may also be important. With the introduction of the Water Framework Directive (WFD) (Council of European Communities, 2000), these concerns have to be translated into actions for the improvement of the UK aquatic environment. Central to this is an assessment of the relative contribution of nitrate and orthophosphate from two main sources, agriculture and population/industry (Neal and Heathwaite, 2005; Neal and Jarvie, 2005); studies of this type are accelerating and are of national importance. Ferrier et al. (2001) examined the relationships between nitrate and orthophosphate and catchment characteristics for Scotland and Muscutt and Withers (1996) investigated phosphorus concentrations in rivers across England and Wales. Correspondingly, several studies within the Land Ocean Interaction Study (LOIS) have studied nutrient and other pollutant fluxes to the North Sea (Jarvie et al., 1997; Robson and Neal, 1997; Neal and Davies, 2003). Also, Nedwell et al. (2002) assessed variations in nutrient loads to UK estuaries and linked them to issues of catchment type.

In this paper, the relationships between catchment characteristics and mean nitrate and orthophosphate concentrations in UK rivers have been examined using the GIS approach as in Davies and Neal (2004). Although only the dissolved forms of nitrogen and phosphorus were considered, there are also potential issues in respect of ammonium and particulate phosphorus. In the study of Davies and Neal (2004), only nitrogen (nitrate, nitrite and ammonium) and land-use catchment characteristics were considered and the regional assessment was confined to the Humber River where areas of urban/industrial cover are disproportionately large relative to the UK. In the present study, the analysis has been extended significantly using national datasets and including information on hydrology in the form of a baseflow index (BFI) and rainfall coupled 
with evaporation to provide a measure of effective rainfall (ER; i.e. the runoff). Introducing BFI enabled identification of regions with permeable bedrock where residence times will be high so that a reduction in nutrient levels within 1015 years as required by the WFD may not be achievable. Effective rainfall is used to consider the dilution effect for different levels of rainfall and evaporation across the UK.

\section{Data sources}

SPATIAL DATA

Five spatial data sources were used in this study.

CEH Wallingford Digital Terrain Model (DTM)(Morris and Flavin, 1990), available at a $50 \mathrm{~m}$ grid interval and a $0.1 \mathrm{~m}$ vertical resolution, was appropriate hydrologically for generating UK catchment boundaries. Ordnance Survey (OS) 1:50 000 digitised contours and spot heights and digitised river networks were used in deriving the DTM.

CEH land-cover Map 2000 (LCM2000) is available as a $25 \mathrm{~m}$ grid covering the UK and is derived from satellite imagery taken between 1998 and 2000. The processes involved in determining the land classes are detailed in Fuller et al. (2002). This study uses the aggregated LCM2000 subclasses which comprise 26 land types across the UK. The land-use data differ from the water quality measurements by approximately five years, a time difference that was not significant for this study, due to the small changes in land use occurring over this period.

Base Flow Index (BFI). This data source exists as a $1 \mathrm{~km}$ UK-wide grid of BFI values (Gustard et al., 1992); these indicate the proportion of base flow in the river for indexing the effect of geology on low flows. The BFI varies between 0 and 1; the higher the value, the higher the proportion of base flow. Catchments with more impermeable surface and subsurface geology (e.g. areas high in clay-rich strata) have low values of BFI while areas with major aquifer sources to the rivers (e.g. Cretaceous Chalk areas) have high BFI.

Standard Annual Average Rainfall (SAAR) data exist as a $1 \mathrm{~km}$ grid based on the average annual rainfall for 19611990, interpolated from the Met Office UK rain gauge network. This value is a good indicator of present day rainfall across the UK.

Actual Evaporation (AE) data are average annual values for 1961 to 1990, taken from monthly MORECS (Hough et al., 1995) data, available on a $40 \times 40 \mathrm{~km}$ grid. Each $40 \mathrm{~km}$ cell was assigned the appropriate average annual AE estimate and the grid resolution was changed to $1 \mathrm{~km}$ to allow for better catchment estimates within the present GIS study. Effective rainfall (ER) was calculated as the difference between SAAR and AE.

\section{TIME SERIES WATER QUALITY DATA}

Nitrate and orthophosphate concentrations were obtained from the databases of the Harmonized Monitoring Network (HMN; Hurley et al., 1996) of the Environment Agency of England and Wales (EA) and from the Scottish Environmental Protection Agency (SEPA). Information on the HMN programme is given by Simpson (1980) while Robson and Neal (1997) describe aspects of its successes and limitations. The monitoring period had to be the same across all the sites, so for pragmatic reasons 1990 to 1995 was used. A criterion for site selection was that usable datasets had to have more than 30 readings for nitrate and orthophosphate at each site, although most had many more readings. For this study, the HMN sites across the UK were chosen to obtain an even spatial distribution covering the range of different land characteristics across the UK as well as a good selection of catchment sizes (43 to $10000 \mathrm{~km}^{2}$ ). For this study, 168 monitoring sites were selected and their locations are shown in Fig. 1. To obtain a sufficient number of test sites within the Humber study, Davies and Neal (2004) used many nested catchments, which may not have been independent of each other. As this study is UK-wide, greater catchment independence was achieved.

\section{Method}

For each HMN site, the mean values of BFI, AE, SAAR and percentage of each land characteristic type within the catchment upstream were extracted automatically within a GIS system using an ArcInfo Aml program. The SAAR and AE values were used to estimate ER. The LCM2000 landcover information was aggregated into classes suggested by Jarvie et al. (2002) but, although all land-cover classes were considered, only the aggregate classes 'mountain, heath and bog', 'arable and horticulture' and 'built up areas and gardens' were found to be relevant to this study and were renamed 'upland', 'arable' and 'urban'. The LCM2000 class of 'improved grassland' includes agriculturally preferred species, generally 'improved' by reseeding and/or fertiliser treatment, which might well contribute to nitrogen and phosphorus levels. However, regression relationships showed that, in comparison with the other land characteristics, improved grassland was neither a significant source of nitrate nor of orthophosphate across the UK and 


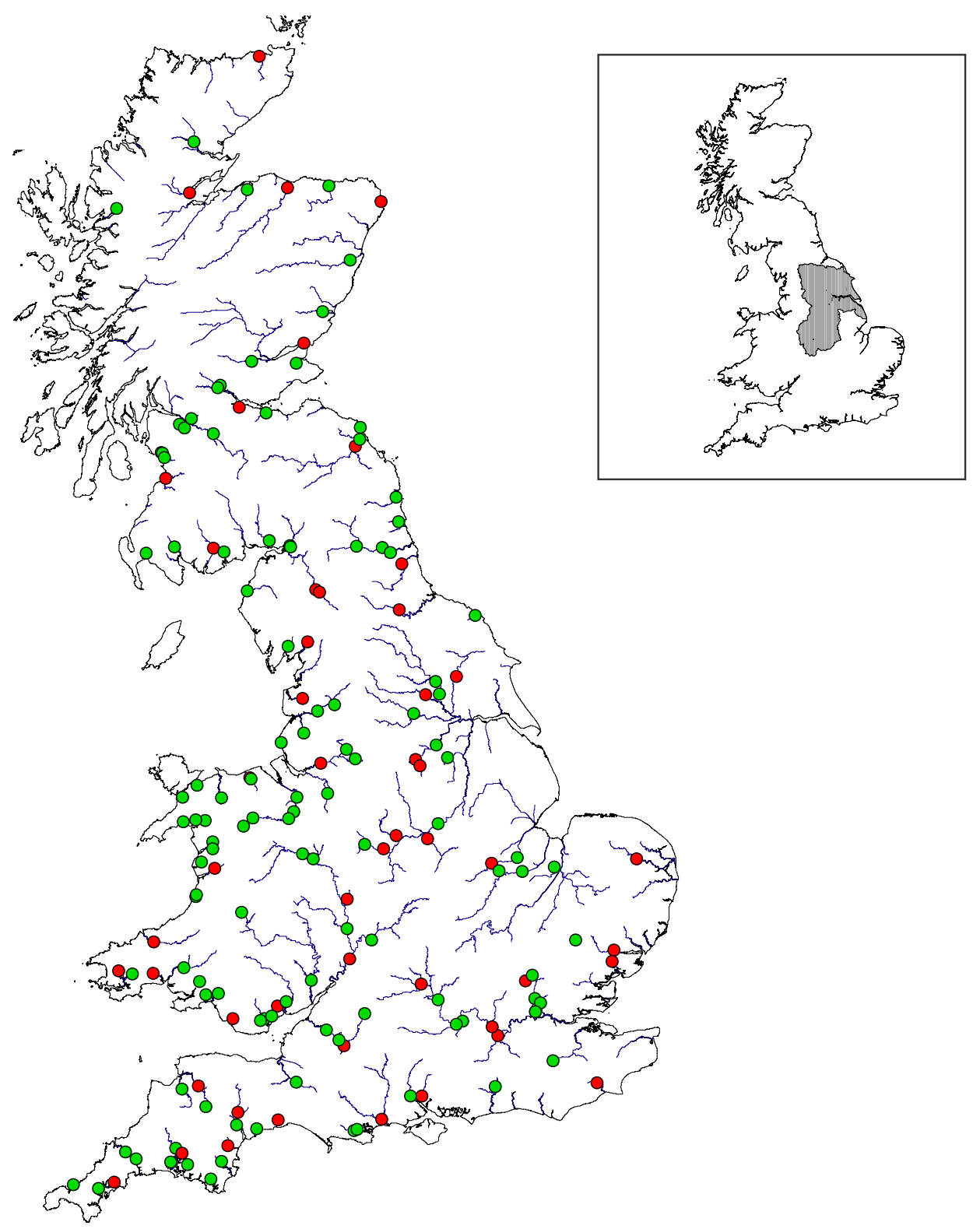

Fig. 1. Water quality monitoring sites used within the study; regression analysis sites (red), test sites (green). Inset shows the Humber region.

so was not included in this study. Areas of high population density tend to be near past and present industrial areas and pollution may result from historic as well as present industry. Population data were investigated by Jarvie et al. (2002) for the Humber; they showed that population density was closely linked to urban area land use. It is difficult to separate these two components since they are so closely linked; hence, only the 'urban' typology was used to represent major population and industrial areas.

Using simple linear regressions, catchment characteristics were compared with the mean nitrate and orthophosphate concentrations to identify those that were related to the mean nitrate and orthophosphate concentrations and were, therefore, relevant for use in a multiple regression analysis. For the multiple regression analysis, the 168 monitoring sites for nitrate and orthophosphate were separated into two groups, the first to derive, by multiple regression, the relationship between the catchment characteristics and the mean nitrate and orthophosphate concentrations and the second to test the validity of the analysis. The first group comprised 51 control sites (Fig. 1), selected on the criteria of an even spatial distribution and a range of catchment sizes and catchment characteristics, while avoiding nested catchments wherever possible. However, for the major basins of the Thames and Severn, nested catchments had to be included to obtain a large and uniform range of sizes 
within the study. In the selection of sites for the multiple regression analysis, as many as were required to satisfy the above criteria were chosen, while keeping the overall number to a minimum, thereby providing more catchments on which to test the multiple regression analysis.

The regression analysis of the 51 control sites was tested in two ways. Firstly, the mean nitrate and orthophosphate concentrations for the 117 sites not included in the analysis (Fig. 1) were compared with the concentrations predicted. Secondly, the data from the Humber region (Fig. 1) were excluded from the regression analysis and used to test the dataset to assess the regression on a sample set with a high urban content; this enabled comparisons between the overall UK study and the Humber area used previously (Davies and Neal, 2004).

\section{Results}

\section{LINEAR REGRESSION RELATIONSHIPS BETWEEN CATCHMENT CHARACTERISTICS AND NITRATE AND PHOSPHORUS}

The linear regressions between catchment characteristics and nitrate $(\mathrm{N})$ and orthophosphate (OP) measurements are in Table 1 and in Figs. 2 and 3; the orthophosphate relation is statistically significant for urban (U) and weak for ER, arable (A) and upland (UP), while nitrate is related to arable, upland and ER and, to a lesser extent, to urban and BFI. In the case of ER and UP, the data are non-linear with respect to nitrate and exhibit a strong inverse relationship with ER. The result is similar but weaker for orthophosphate.

\section{NITRATE AND ORTHOPHOSPHATE REGRESSION ANALYSIS ON LOG-TRANSFORMED DATA.}

A multiple regression analysis was made between nitrate and orthophosphate concentrations and the catchment characteristics identified above for the 51 selected catchments across the UK. Log transformed data were used to linearise the relationships between determinands and eliminate prediction of negative water quality concentrations. For nitrate $(\mathrm{N})$, the non-linear behaviour occurs with upland (UP\%) and ER (mm), while for orthophosphate (OP) the non-linear behaviour is with ER.

For $\mathrm{N}$, mean nitrate concentration $\left(\mathrm{mg} \mathrm{NO}-\mathrm{N} \mathrm{L}^{-1}\right)$ the relevant catchment characteristics for 51 sites are arable (A\%), urban (U\%), $0<\mathrm{BFI}<1$, upland (UP\%) and ER (mm) and the regression is:

$$
\begin{aligned}
\ln N=3.378+0.638 \ln B F I & +0.173 \ln A+0.317 \ln U \\
& -0.253 \ln U P-0.332 \ln E R \\
\mathrm{R}^{2}=0.88, \mathrm{p}<0.001 . &
\end{aligned}
$$

For OP, mean orthophosphate concentrations (mg $\mathrm{P} \mathrm{L}^{-1}$ ), the relevant catchment characteristics for the 51 sites are $U$ and ER and the regression is:

$$
\begin{aligned}
& \ln O P=3.07+0.693 \ln U-0.948 \ln E R \\
& \mathrm{R}^{2}=0.86, \mathrm{p}<0.001
\end{aligned}
$$

As a further test of the robustness of the method, the seven Humber sites were removed and the regression for the 44 remaining sites is:

$$
\begin{aligned}
\ln N & =3.13+0.765 \ln B F I+0.193 \ln A+0.295 \ln U \\
\mathrm{R}^{2} & =0.83, \mathrm{p}<0.001 .
\end{aligned}
$$

\begin{tabular}{|c|c|c|c|c|c|}
\hline & Arable \% & Urban \% & Upland \% & $B F I$ & $\begin{array}{l}\text { Effective } \\
\text { rainfall }(\mathrm{mm})\end{array}$ \\
\hline nitrate $\mathrm{mg} \mathrm{N} \mathrm{L}^{-1}$ & 0.59 & 0.30 & 0.55 & 0.25 & 0.58 \\
\hline orthophosphate mg $\mathrm{P} \mathrm{L}^{-1}$ & 0.17 & 0.60 & 0.19 & 0.03 & 0.26 \\
\hline Effective rainfall & 0.57 & 0.16 & 0.55 & 0.21 & - \\
\hline BFI & 0.28 & 0.03 & 0.34 & - & - \\
\hline Upland cover \% & 0.55 & 0.13 & - & - & - \\
\hline Urban cover \% & 0.04 & - & - & - & - \\
\hline
\end{tabular}

The corresponding regression for orthophosphate is

$$
\ln O P=2.806+0.725 \ln U-0.906 \ln E R
$$

$$
\mathrm{R}^{2}=0.84, \mathrm{p}<0.001
$$

Table 1. $\mathrm{r}^{2}$ values, showing the positive and negative relationships between the variables. The values in italics refer to a negative relationship. 

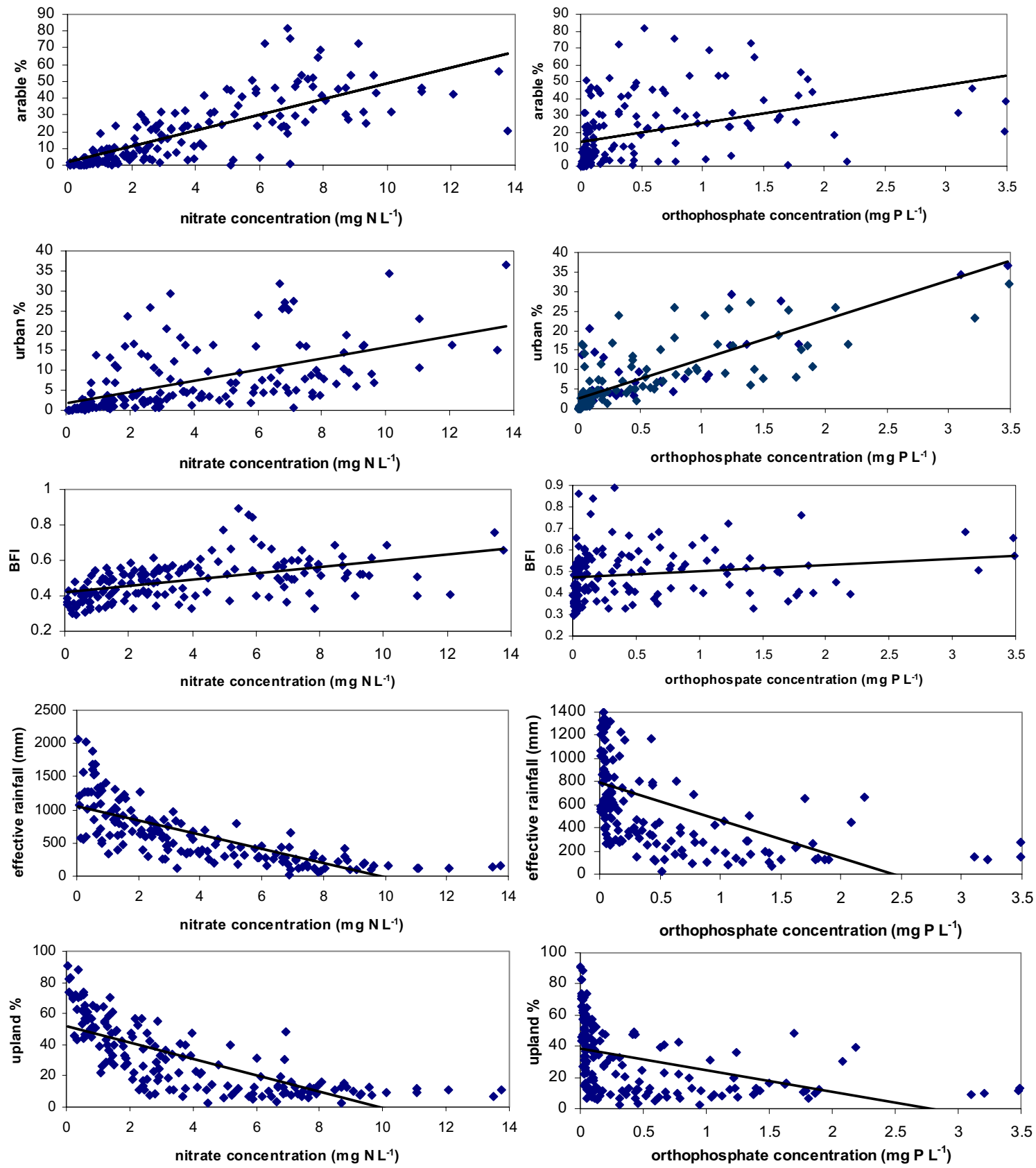

Fig. 2. Nitrate and orthophosphate concentrations and their relationship with other catchment characteristics.

This second analysis, without the Humber sites, was undertaken so that the regression analysis could be tested on an entire region not used in the regression analysis. The regression analyses including the Humber area are more reliable than those excluding it, as they are based on a larger sample covering all catchment characteristics across the UK. The differences between the two regression analyses, however, are not greatly significant.
TESTING THE NITRATE AND ORTHOPHOSPHATE MULTIPLE REGRESSION EQUATIONS

To verify the nitrate and orthophosphate multiple regression analyses, two tests were applied. Firstly, the predicted mean nitrate and orthophosphate concentrations from the multiple regression equations using 51 sites were compared with the observed mean concentrations at the 117 test sites. Secondly, the predicted mean nitrate and orthophosphate concentrations from the multiple regression analysis without the Humber sites were tested using the Humber sites. 

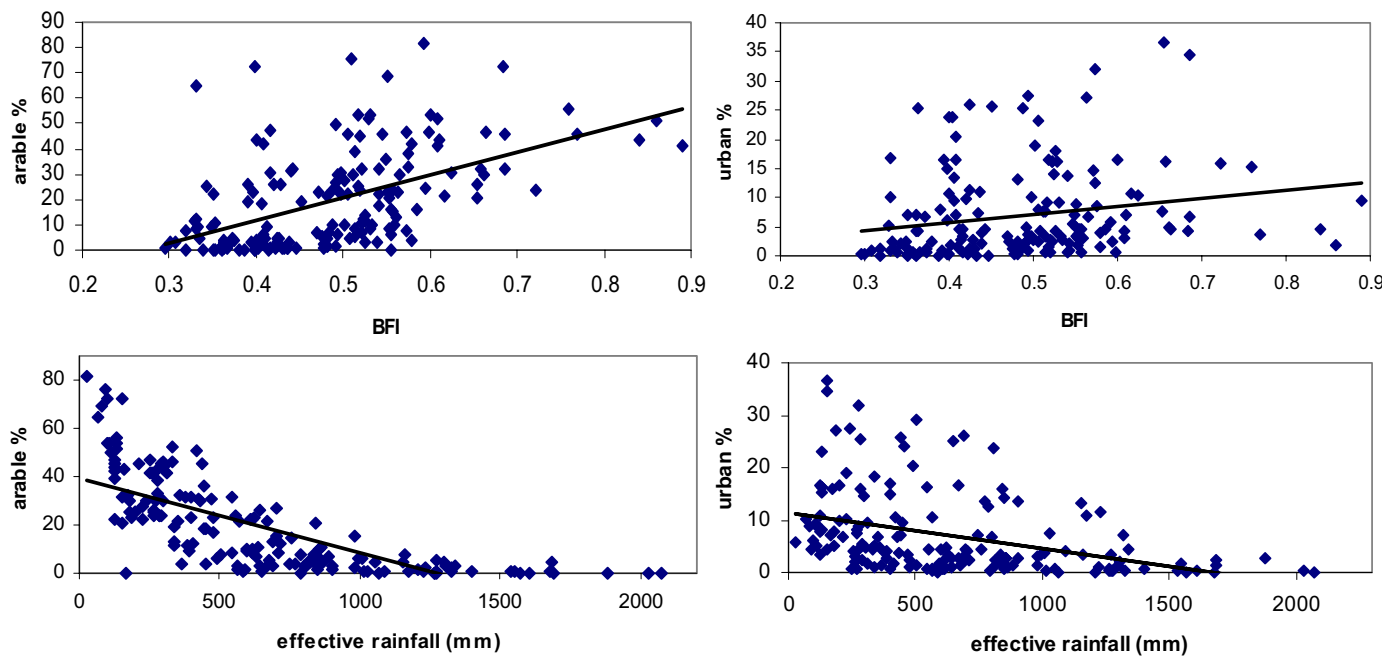

Fig. 3. Relationships between catchment characteristics

Figure $4 \mathrm{a}$ shows observed and predicted mean nitrate concentrations for the 117 test sites $\left(r^{2}=0.76\right)$. Figure $4 b$ shows the results of using the regression equation excluding the Humber sites, to compare the predicted and observed results within the Humber region $\left(r^{2}=0.86\right)$. Both tests prove the feasibility of estimating nitrate concentrations from catchment characteristics on a UK-wide scale. While for the first case the fit is well within statistical error, in the second case, there is moderate underestimation in the prediction of nitrate concentrations.

One extreme outlier is in Fig. 4a, where the observed concentration is $6.87 \mathrm{mg} \mathrm{N} \mathrm{L}^{-1}$ and the concentration predicted is $15.71 \mathrm{mg} \mathrm{N} \mathrm{L}^{-1}$. This site is on the Level Main Drain at Outwell, situated in the flat marshland fen area near Kings Lynn. The catchment boundary generated by the DTM contains $82 \%$ arable and the lowest ER resulting in the overestimated predicted value. This catchment is

(a)

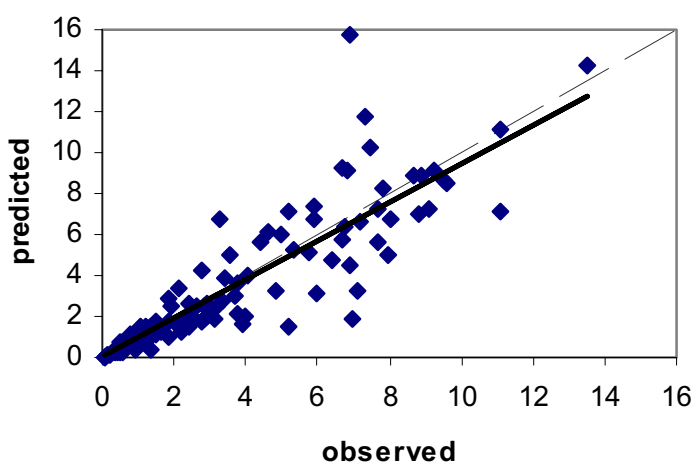

particularly difficult to model because of uncertainties in delineating catchment boundaries in flat areas, especially within drains where flow directions and natural flow paths can be altered.

Figure 5 shows the corresponding results of the two tests for orthophosphate. Figure 5a shows observed and predicted mean orthophosphate concentrations for the 117 test sites $\left(r^{2}=0.46\right)$. Figure $5 b$ shows the results of using the regression equation without the Humber sites, to compare the predicted and observed results in the Humber region $\left(\mathrm{r}^{2}\right.$ $=0.93$ ).

At low to moderate orthophosphate concentrations, observed and predicted values are reasonably close to a $1: 1$ relationship. However, at higher orthophosphate concentrations, using this method results in a significant underestimation. To assess why there might be a discrepancy in goodness of fit at high (observed) orthophosphate

(b)

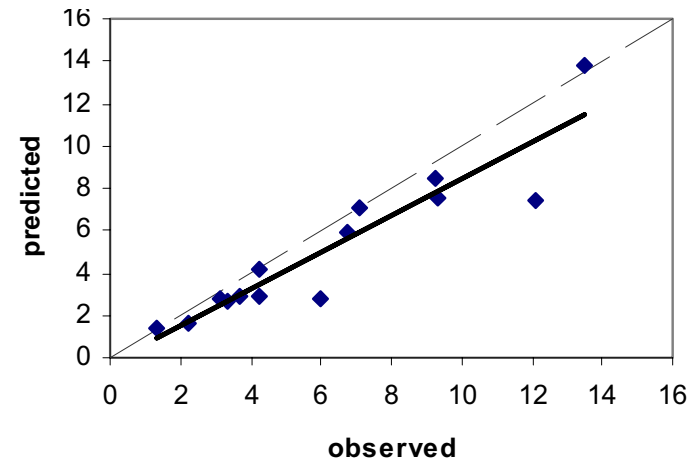

Fig.4. Observed and predicted nitrate concentrations ( $m g \mathrm{NL}^{-1}$ ); (a) 117 test sites across the UK, (b) Humber sites only. Dashed line is 1:1 relationship 

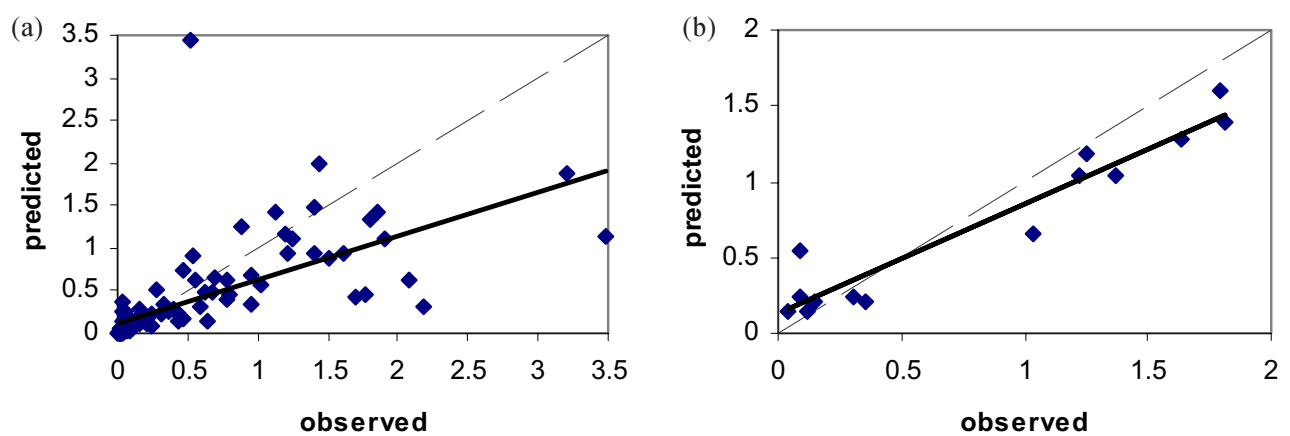

Fig. 5. Observed and predicted orthophosphate concentrations (mg $P L^{-1}$ ); (a) 117 test sites across the UK, (b) Humber sites only. Dashed line is $1: 1$ relationship.

concentrations, individual monitoring points were examined. This revealed that orthophosphate concentrations were most severely under-predicted for sites just downstream of sewage treatment works (STW). Thus, the discrepancy can be linked to within-river processing; the further from the point source a STW is, the greater the loss of orthophosphate from the water column. Therefore, in the case of orthophosphate, an additional catchment parameter is needed linking to the upstream location of STW inputs.

In Fig. 5a, there is one extreme outlier (predicted $=3.4 \mathrm{mg}$ $\left.\mathrm{P} \mathrm{L}^{-1}\right)$. This catchment is in the east of England and has the lowest ER in the study, resulting in the over-prediction of orthophosphate.

\section{Discussion}

The analysis in this paper illustrates the feasibility and limitations of estimating nitrate and orthophosphate concentrations across the UK in relation to catchment characteristics.

For nitrate, a reasonable estimate of average concentration is obtained from catchment characteristics. Nitrate is linked to arable areas and, to a lesser extent, to urban cover. The results are consistent with those of Ferrier et al. (2001) whose studies on the water quality of Scotland, based on an analysis of HMN data, showed nitrogen concentrations in rivers to be highly correlated with the extent of arable land. The results for nitrate in this study differ from those of Davies and Neal (2004) for the Humber catchment, where the dominant land characteristic was urban, indicating that the Humber region is more industrial than agricultural. This shows the importance of the size and area used in such a study. As well as land characteristics, nitrate is related to catchment characteristics such as ER and BFI. Higher mean nitrate concentrations tend to be in areas of low ER and high BFI (Fig. 6).

The estimation of orthophosphate concentrations using this GIS/regression method is poorer than that for nitrate. The relationships between orthophosphate concentrations and catchment characteristics show that urban content and to a much lesser extent ER may influence orthophosphate concentrations across the UK. The extremely weak linkage between orthophosphate concentrations and arable areas

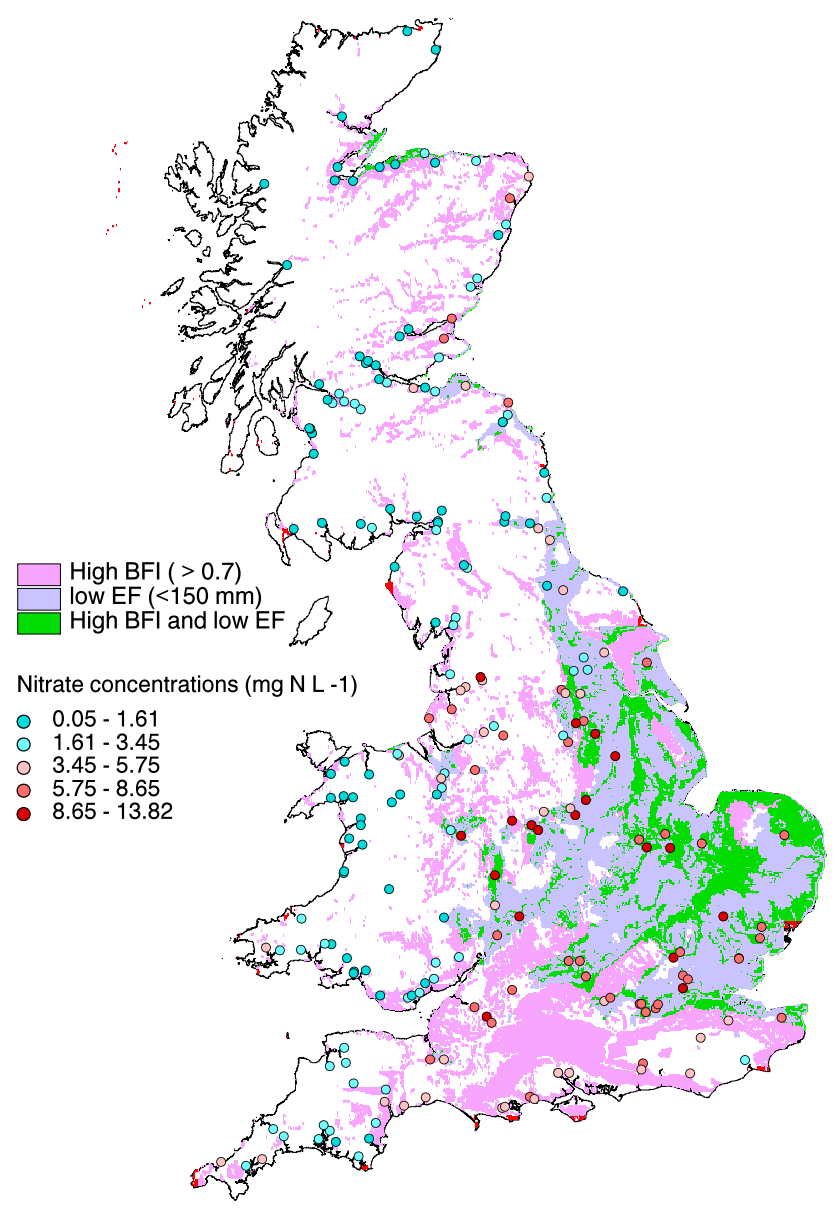

Fig. 6. Areas of high BFI and low EF overlain by observed mean HMN nitrate concentrations 
may be in part because of the likelihood that most of the agricultural phosphate contribution is in particulate form. Orthophosphate was chosen for this study because there were more data available for this form of phosphorus. No relationships were found between orthophosphate and improved grassland cover, although Ferrier et al. (2001) report relationships between grassland cover and orthophosphate concentrations and high correlations between phosphates and urban catchments in Scotland. It may be that, on a UK scale, urban inputs are more dominant and mask any relationships between improved grassland and orthophosphate. For orthophosphate, this study stresses the importance of urban industrial areas as compared with more rural, agricultural areas, in good agreement with the findings of Neal and Jarvie (2005) and Jarvie et al. (2006a). Here, there was under-prediction of orthophosphate concentrations when the monitoring points were just downstream of STW inputs. In one important respect, orthophosphate differs from nitrate in that it is more reactive and can be removed from the water column. Linear regression models start to break down when there are within-river losses. Thus, in the case of inputs from STWs, the loss of orthophosphate from the water column will increase with distance from the effluent source because of the ability of the sediment and biota to take up orthophosphate (Jarvie et al., 2005, 2006b). Indeed, the difference between observed and predicted is plotted against urban coverage in Fig. 2; the pattern shows both a general but scattered relationship and a trace of a linear feature of higher orthophosphate to percentage of urban cover that may well reflect the effect of a STW in the vicinity. A more detailed GIS analysis is required, including STW inputs, because they are important in predicting orthophosphates.

The present findings on orthophosphate are consistent with the results of Muscutt and Withers (1996); from Environment Agency data, they concluded that the widespread orthophosphate enrichment of English and Welsh rivers is largely a consequence of point source inputs. However, because their data were more representative of base flow conditions, the contribution from agriculture may have been underestimated. This and previous studies provide an important caveat against the commonly-held view that agricultural sources of phosphorus are particularly problematic in respect of riverine contamination and eutrophication.

\section{Conclusion and wider comment}

The value of catchment characteristics in describing the distributions of nitrate and orthophosphate has been demonstrated. The results of the GIS/regression approach are dependent on the area being studied, so a wide coverage of catchment types is highly desirable. Thus, the Davies and Neal (2004) results for nitrate in the urban-dominated region in the Humber showed that urban is the land characteristic which is most important in determining nitrate concentrations. However, when the analysis is applied to landscapes across the UK as a whole, arable proves to be more important. For data mining and broadly-based national assessment, national datasets and integrateable resources are invaluable. This study has also shown that the prediction of orthophosphate concentrations from catchment characteristics is less certain than that for nitrate, probably because of discharges from STWs and within-river losses. Indeed, the tendency to underestimate orthophosphate at locations just downstream of STWs illustrates the localised importance of effluent discharges. While the size of the population in the upstream area of a catchment partially defines orthophosphate concentrations in the river, so too does the location of the entry point of these effluent discharges. Thus, the greatest impact of the point sources will be just downstream of their entry to the river: withinriver hydrobiochemical processing leads to loss of orthophosphate from the water column, a loss that increases with increasing distance of travel (i.e. increasing water residence time) downstream of the effluent input. Even for rural areas, these localised point sources can have a major impact on orthophosphate levels within the river just downstream of their entry points. As Neal et al. (2006) argue, there has to be a more holistic consideration for orthophosphate in relation to rural farming, rural settlement, peri-urban and urban vectors. Further work on looking at ways of separating population from industrial inputs and characterising point source distributions would be beneficial in estimating orthophosphate concentrations. One such promising approach is using GIS-based catchment and locality analysis (Jarvie et al., 2002).

\section{Acknowledgements}

The authors are indebted to the reviewers whose critical comments were helpful in the production of a much better paper. Within $\mathrm{CEH}$, the work was underpinned in part by funds linked to the LOIS and EUROCAT programmes. The analysis in this paper is stimulated in particular by a new initiative, the Catchment Hydrology, Resources, Economics and Management (ChREAM) project, funded under the Rural Economy and Land Use (RELU) programme of ESRC, BBSRC and NERC. 


\section{References}

Council of European Communities, 2000. Directive 2000/60/EC of the European Parliament and of the Council establishing a framework for the Community action in the field of water policy. CEC, L 327, P. 0001-0073. (http://europa.eu.int/comm/ environment/water/water-framework/index en.html)

Davies, H. and Neal, C., 2004. GIS based methodologies for assessing nitrate, nitrite and ammonium distributions across a major UK basin, the Humber. Hydrol. Earth Syst. Sci., 8, 823833.

EA, 2000. Aquatic Eutrophication of England and Wales: A management strategy. Environment Agency, Bristol, UK. 32pp.

Ferrier, R.C., Edwards, A.C., Hirst, D., Littlewood, I.G., Watts, C.D. and Morris, R., 2001. Water quality of Scottish rivers: spatial and temporal trends. Sci. Total Envir., 265, 121-152.

Fuller, R.M., Smith, G.M., Sanderson, J.M., Hill, R.A. and Thompson. A.G., 2002. The UK land-cover Map 2000: Construction of a parcel-based vector map from satellite images. Cartogr. J., 39, 15-5.

Gustard, A., Bullock, A. and Dixon, J., 1992. Low Flow Estimation in the United Kingdom. IH Report 108, Wallingford, UK.

Hough, M., Palmer, S., Weir, A., Lee, M. and Barrie, I., 1995. The Meteorological Office Rainfall and Evaporation Calculation System: MORECS Version 2.0. An update to Hydrological Memo. No. 45, Met Office, UK.

Hurley, M.A., Currie, J.E., Gough, J. and Butterwick, C.A., 1996. Framework for the analysis of Harmonised Monitoring Scheme data for England and Wales. Environmetrics, 7, 379-390.

Jarvie, H.P., Neal, C. and Tappin, A.D., 1997. European landbased pollutant loads to the North Sea: an analysis of the Paris Commission data and review of monitoring strategies. Sci. Total Envir., 194/195, 41-58.

Jarvie, H.P., Oguchi, T. and Neal, C., 2002. Exploring the linkages between river water quality and watershed characteristics using GIS-based catchment and locality analysis. Reg. Environ. Change, 3, 36-50.

Jarvie, H.P., Jürgens, M.D., Williams, R.J., Neal, C., Davies, J.J.L., Barrett, C. and White, J., 2005. Role of river bed sediments as sources and sinks of phosphorus across two major eutrophic UK river basins: the Hampshire Avon and Herefordshire Wye. $J$. Hydrol., 304, 51-74.

Jarvie, H.P., Neal, C. and Withers P.J.A., 2006a. Sewage-effluent phosphorus is a greater risk to river eutrophication than agricultural phosphorus. Sci. Total Envir., (in press).

Jarvie, H.P., Neal, C., Jürgens, M.D., Sutton, E.J., Neal, M., Wickham, H.D., Hill, L.K., Harman, S.A., Davies, J.J.L., Warwick, A., Barrett, C., Griffiths, J., Binley, A., Swannack, N and McIntyre, N., 2006b. Within-river nutrient processing in Chalk streams: the Pang and Lambourn, UK. J. Hydrol., (in press).
Morris, D.G. and Flavin, R.W., 1990. A Digital Terrain Model for Hydrology. 4th International Symposium on Spatial Data Handling, July 23-27, 1990, Zurich, Switzerland.

Muscutt, A.D. and Withers, P.J.A., 1996. The phosphorus content of rivers in England and Wales. Water Res., 30, 1258-1268.

Neal, C. and Davies, H., 2003. Water quality fluxes for eastern UK rivers entering the North Sea: a summary of information from the Land Ocean Interaction Study (LOIS). Land Ocean Interaction: Processes, Functioning and Environmental Management: a UK Perspective. Sci. Total Envir., 314-316, 821882.

Neal, C. and Heathwaite, A.L., 2005. Nutrient mobility within river basins: a European perspective. J. Hydrol., 304, 477-490.

Neal, C. and Jarvie, H.P., 2005. Agriculture, community, river eutrophication and the water framework directive. Hydrol. Process., 19, 1895-1901.

Neal, C., Neal, M., Hill, L. and Wickham, H., 2006. River water quality of the River Cherwell: an agricultural clay-dominated catchment in the upper Thames Basin, south-eastern England. Sci. Total Envir., (in press).

Neal, C., Reynolds, B., Neal, M., Hughes, S., Wickham, H., Hill, L., Rowland, P. and Pugh, B. 2003a. Soluble reactive phosphorus levels in rainfall, cloud water, throughfall, stemflow, soil waters, stream waters and groundwaters for the Upper River Severn area, Plynlimon, Mid Wales. Sci. Total Envir., 314/316, 99-120.

Neal, C., Reynolds, B., Neal, M., Hill, L., Wickham, H. and Pugh, B. 2003b. Nitrogen in rainfall, cloud water, throughfall, stemflow stream water and groundwater for the Plynlimon catchments of mid-Wales. Sci. Tot. Environ., 314/316, 121-152.

Nedwell, D.B., Dong, L.F., Sage, A. and Underwood, G.J.C., 2002. Variations of the nutrients loads to the mainland UK estuaries: Correlation with catchment areas, urbanization and coastal Eutrophication. Estuar. Coast. Shelf Sci., 54, 951-970.

Robson, A.J. and Neal, C., 1997. A summary of regional water quality for Eastern UK rivers. Sci. Total Envir., 194/195, 1538.

RPA, 2003. Water Framework Directive - Indicative costs of agricultural measures. Final report prepared for the Department for Environment, Food and Rural Affairs, by Risk and Policy Analysts Limited in association with ADAS and CEH, 48pp. (www.defra.gov.uk/environment/water/wfd/index.htm).

Pretty, J.N., Mason, C.F., Nedwell, D.B., Hine, R.E., Leaf, S. and Dils, R., 2003. Environmental Costs of Freshwater Eutrophication in England and Wales. Environ. Sci. Technol., 32, 201208.

Simpson, E.A., 1980. The harmonisation of the monitoring of the quality of rivers in the UK. Hydrolog. Sci. Bull., 25, 1-13. 